\title{
A MEDIAÇÃO PARTICIPATIVA COMO EXPERIÊNCIA FORMATIVA PROFISSIONAL
}

\author{
Fabiana Rodrigues Santos ${ }^{1}$, Luís Paulo Carvalho Piassi ${ }^{2}$ \\ ${ }^{1}$ Doutoranda em Ensino de Ciências pela Faculdade de Educação da Universidade de São Paulo - USP. Coordenadora do \\ projeto M.A.R.I.A. na formação profissional de graduandos de cursos diversos da EACHUSP. E-mail: fabisantos@usp.br \\ ${ }^{2}$ Doutor em Educação pela Faculdade de Educação da Universidade de São Paulos - USP. Docente da Escola de Artes, \\ Ciências e Humanidades da Universidade de São Paulos - USP.
}

\section{RESUMO}

Este artigo apresenta alguns dos resultados obtidos na criação de um ambiente de estudos e formação de forma participativa. Tal proposta foi desenvolvida na linha de pesquisa M.A.R.I.A (Manifestações da Alegria e da Recreação na Arte-Ciência), que trata-se de um grupo de estudos que realiza divulgação científica por meio do lúdico. Tendo em vista esse foco de atuação da linha verificamos se a criação de um contexto participativo gera nos mediadores das ações de divulgação científica a ideia de empoderamento e se o ambiente construído é favorável para que os alunos sejam protagonistas na execução de seus projetos pessoais de pesquisa. Para que isso fosse viável, buscamos criar no grupo um ambiente de pesquisa dialógico para a produção de conhecimento científico de maneira colaborativa em diversos âmbitos, partindo da ideia de promoção de sujeitos colaboradores e participativos do processo; da formação de sujeito de aprendizagem, de organização e promotores de um ambiente que possibilite as interações e experiências. A coleta de dados do processo se deu por meio de entrevistas em vídeo, gravações dos áudios das reuniões, diário de bordo, recursos de web e documentos elaborados pelos integrantes do grupo. Tais materiais foram analisados e percebemos que a proposta de mediação por meio da metodologia participativa fez com que os alunos se sentissem livres para atuar e se encarregarem de seu processo de formação, atuando como protagonistas em suas pesquisas

Palavras-chave: Participação. Mediação. Formação. Empoderamento.

\section{PARTICIPATIVE MEDIATION AS A PROFESSIONAL TRAINING EXPERIENCE}

\begin{abstract}
This article presents some of the results obtained in the creation of an environment of studies and training in a participatory way. This proposal was developed in the line of research M.A.R.I.A. (Manifestations of Joy and Recreation in Art-Science), which is a group of studies that carries out scientific dissemination through the ludic. In view of this focus of the line, we verified whether the creation of a participatory context generates the idea of empowerment in the mediators of the actions of scientific dissemination and the built environment is favorable for the students to be protagonists in the execution of their personal research projects. For this to be feasible, we seek to create in the group an environment of dialogical research for the production of scientific knowledge in a collaborative way in several spheres, starting from the idea of promoting collaborating and participatory subjects of the process; the formation of a learning subject, an organization and promoters of an environment that enables interactions and experiences. The data collection of the process was done through video interviews, recordings of meetings audios, logbook, web resources and documents prepared by the members of the group. These materials were analyzed and we realized that the proposal of mediation through participatory methodology made the students feel free to act and put themselves in charge of their training process, acting as protagonists in their research.
\end{abstract}

Keywords: Participation. Mediation. Training. Empowerment. 


\section{INTRODUÇÃO}

Entendemos que a formação profissional cumpre o duplo objetivo de contribuir para o desenvolvimento pessoal e profissional do estudante. O acesso a ele por meio de outros contextos formativos, além do oferecido em sala de aula no decorrer de sua formação, pode ser importante no sentido de fomentar tal desenvolvimento, contribuindo para uma maior qualificação por meio de experiências e práticas. Neste sentido, visualizamos que o contexto de projetos de extensão possa ser um meio de ampliar a qualidade da formação do estudante e propiciar ambientes de atuação na prática, nos quais eles possam realizar ações ativamente tendo em vista suas formações. Porém, entendemos que tal contexto deve ser democrático e inclusivo, no qual o participante se veja como importante e tenha espaço para ser atuante.

Tendo isso em vista, buscamos neste artigo apresentar nossa proposta de criação de um ambiente formativo de maneira participativa e verificar se tal contexto foi realmente democrático, se gerou empoderamento nos participantes e se contribuiu no âmbito individual tendo em vista as escolhas profissionais de cada integrante. A pesquisa aqui apresentada é importante por promover a possibilidade de ampliação de ações formativas com um viés democrático, por meio da criação de ambientes de estudo, pesquisa e formação que contribua qualitativamente para os estudantes. A escolha metodológica para a tomada de dados se baseou na investigação praxeológica de OliveiraFormosinho (2015 a,b,c).

A proposta se deu no contexto do Projeto de extensão "Banca da Ciência"1, mais especificamente, na linha de pesquisa M.A.R.I.A2 que realiza um importantíssimo trabalho na

\footnotetext{
${ }^{1}$ Banca da Ciência: difusão dialógica da ciência na primeira infância e pré-adolescência - O projeto de pesquisa pretende investigar e realizar desenvolvimentos teóricos em torno da modalidade de divulgação científica que denominamos difusão dialógica da ciência (DDC) que se caracteriza por dar voz e mobilizar atores diversos em torno de práticas de comunicação da ciência, tendo como foco dois públicos: primeira infância (até 6 anos de idade), denominada vertente JOANINHA e pré-adolescência (10 a 14 anos), denominada vertente ALICE. Esses públicos são atendidos nas sete linhas de pesquisa: A.N.N.A.S., D.I.A.N., E.M.M.A., L.I.R.A., L.U.C.I.A., M.A.R.I.A. e R.I.T.A. Conta com o incentivo do Programa Institucional de Bolsa de Iniciação à Docência (PIBID) da Fundação CAPES do Ministério da Educação e também do Programa Unificado de Bolsas de Estudo para Estudantes de Graduação (PUB) da política de apoio à permanência e formação estudantil da USP. Diversos são os projetos aqui realizados voltados para o ensino de ciências, dentre eles com, romance policial (SANTOS, 2013), com histórias em quadrinhos (NASCIMENTO JUNIOR, F. A, 2017) e com o riso (RAMOS, , 2016).

${ }^{2}$ Manifestações da Alegria e da Recreação na Arte-Ciência, articulada às práticas do lúdico, do humor e do brincar.
}

formação de multiplicadores na dimensão da divulgação científica por meio do brincar, evidenciando as diversas manifestações da dimensão lúdica que a atividade científica subentende, como observado por Bronowski (1998). A proposta da linha é levantar e promover discussões éticas sobre sustentabilidade, inclusão social, o papel da mulher na ciência, entre outras, e particularmente a igualdade de gênero, que raramente são abordadas no contexto dos saberes das ciências naturais em suas diversas manifestações. No decorrer da pesquisa, a consolidação do foco da linha se deu por meio de diversas discussões e de estudos diversos sobre a dimensão lúdica e o brincar (SERRÃO; CARVALHO, 2011; KISHIMOTO, 2012; BOMTEMPO, 2012; BOMTEMPO, 2015).

A linha M.A.R.I.A é composta por estudantes da EACHUSP $^{3}$ de cursos de graduação bem distintos, tais como Lazer e Turismo, Gestão Ambiental, Gestão de Políticas Pública, Têxtil e Moda, Marketing, entre outros; alunos de pós graduação e professores doutores, bem como, os profissionais, as crianças e os adolescentes dos espaços formais e não-formais em que atuamos. $O$ foco inicial é a formação de recursos humanos em nível de graduação, englobando estudantes de licenciaturas, mas não se restringindo à formação de professores em si, uma vez que incorpora outros futuros profissionais que podem se beneficiar do tipo de ação proposta nos projetos.

Neste ambiente de estudos propomos a formação de sujeitos de aprendizagem, com a construção de um ambiente participativo que possibilite as interações e experiências de maneira democrática, e que respeite e apresente as diversidades plurais de cada um. Neste sentido, Oliveira-Formosinho e Formosinho (2015) nos auxiliará e nos fornecerá embasamento teórico metodológico para essa condução conforme a pedagogia participativa da formação em contexto proposta por eles. A esse respeito eles dizem que os saberes pedagógicos são construídos na ação situada, articulada e integrada com as concepções teóricas e com as crenças. Isso significa dizer que deve-se:

Convocar crenças, valores e
princípios, analisar práticas
e usar saberes e teorias
constitui o movimento
triangular de criação da
pedagogia. A pedagogia
sustenta- se, assim, numa

\footnotetext{
${ }^{3}$ Escola de Artes, Ciências e Humanidades da Universidade de São

Paulo (USP), localizada na zona leste da cidade de São Paulo.
} 
práxis, isto é, numa ação fecundada na teoria e sustentada num sistema de crenças. A práxis é o locus da Pedagogia e, portanto, torna-se o locus para o desenvolvimento do conhecimento pedagógico (OLIVEIRA-FORMOSINHO; FORMOSINHO, 2015, p.1).

A democracia está presente ao se pensar na finalidade educativa, está presente no quotidiano vivido e na missão de promoção da igualdade e inclusão de todas as diversidades. Portanto, essa visão democrática deve estar presente em todos os níveis da intervenção educativa, passando a ser uma visão de mundo

Este conjunto de pontos de partida leva à afirmação do respeito por todos os indivíduos e grupos envolvidos nos processos educativos, ao diálogo intercultural entre grupos e indivíduos envolvidos nos processos pedagógicos, à promoção de colaboração na aprendizagem, à procura de sucesso educativo para todos, num contexto de respeito pelos direitos humanos, incluindo o respeito pelos direitos da criança, entre os quais se conta o direito a aprender. o desenvolvimento da identidade das crianças e dos profissionais é também um processo de desenvolvimento da identidade enquanto aprendizes (OLIVEIRAFORMOSINHO;

FORMOSINHO, p.6, 2015).

Acreditamos que a criação desse contexto gera empoderamento nos participantes que ali estão, pois o intuito é conseguir favorecer individualmente cada integrante por meio da orientação de seus projetos individuais e ao mesmo tempo que seja conduzido com a ideia de unidade. Neste artigo apresentaremos a forma como tudo se deu e os resultados alcançados.

\section{MÉTODOS}

Como a proposta dessa pesquisa é a promoção da formação de estudantes de graduação por meio da formação de sujeitos de aprendizagem, é necessária a construção de um ambiente participativo que possibilite as interações e a vivência de experiências de maneira democrática. Além disso, que tal contexto seja respeitoso às diversidades plurais de cada um, haja vista, que, no grupo M.A.R.I.A há integrantes de cursos de graduação bem distintos e cada qual, com suas impressões, interesses e características que os constituem e os definem. A proposta dessa pesquisa é construir um ambiente de formação que consiga favorecer individualmente cada integrante por meio da orientação de seus projetos individuais e ao mesmo tempo que seja conduzido com a visão de unidade e que o foco central da linha de pesquisa, da divulgação da ciência por meio do lúdico seja realizado. Para isso, entendemos que a pedagogia em participação pela investigação praxeológica (OLIVEIRAFORMOSINHO, 2015a,b,c) nos auxiliará e nos fornecerá embasamento teórico metodológico para essa condução.

Tendo isso em vista, a princípio realizamos pesquisa bibliográfica para entender a proposta da pedagogia em participação. Por meio do estudo entendemos o quão sutil deve ser o trato com os atores que participam do contexto para que o empoderamento surja e para que se sintam ouvidos, sendo essa a proposta da formação em contexto. Pensando nisso, articulamos e construímos um contexto participativo que fosse democrático e que respeitasse e apresentasse as diversidades plurais de cada um, com o intuito de que gerar nos graduandos a sensação de pertencimento e assim se engajarem em um projeto que deixa de ser do grupo e passa a ter um viés pessoal.

Os graduandos chegaram à linha de pesquisa de três formas: por meio de um convite realizado em uma disciplina do ciclo básico lecionada por um dos professores coordenadores do projeto para que os alunos participem como voluntários; por convite de alunos envolvidos no projeto ou por meio de inscrição em processo seletivo de bolsas. No período estudado, primeiro semestre de 2018, o grupo era formado por seis alunos de graduação, sendo um voluntário e cinco bolsistas ${ }^{4}$. Dentre os participantes, três já estavam na linha de pesquisa M.A.R.I.A. e três iniciaram no primeiro semestre de 2018, sendo que, estes vieram de outras linhas de pesquisa do projeto

\footnotetext{
${ }^{4}$ Financiados pelo Programa Unificado de Bolsas de Estudos para Estudantes de Graduação (PUB) que integra a Política de Apoio à Permanência e Formação Estudantil da USP
} 
Banca da Ciência, que também realizavam o trabalho de divulgação científica, entretanto, com outro foco e metodologia. As reuniões formativas aconteciam semanalmente por um período de duas horas e as intervenções tinham datas prédefinidas no início do semestre e ocorriam quinzenalmente.

O direcionamento dos graduandos foi voltado para seus projetos pessoais de pesquisa, portanto eles foram orientados a formularem seus projetos tendo em vista suas formações profissionais, ou seja, que levassem em consideração seus interesses pessoais, bem como, interesses profissionais e que concomitantemente estivesse articulado com a proposta da linha M.A.R.I.A. Tal vertente objetivou que a produção de conhecimento científico fosse colaborativa em diversos âmbitos, partindo da ideia de promoção de pessoas colaboradoras e participativas do processo; da formação de sujeitos de aprendizagem, pela promoção de um ambiente que possibilite tais interações e trocas de experiências.

Nesse período os integrantes como um todo focam em resolver a seguinte questão: qual seria realmente o objetivo da linha de pesquisa M.A.R.I.A.? Os momentos iniciais de discussões tem isso como foco, e os estudos voltam-se para tal questionamento, afinal, entender isso daria direcionamento para a elaboração de propostas de atividades. Tais inquietações resultaram na ideia central que norteia a linha: o foco é a dimensão lúdica e o brincar. A partir disso, nesse seguimento os projetos individuais dos alunos são construídos e assim iniciados.

Todas as intervenções planejadas foram alocadas no calendário pré-determinado pelo grupo no início do semestre facilitando assim planejamento de todos para a realização das intervenções de divulgação científica, produto final dos estudos. Tais intervenções aconteceram na prática em uma unidade do CCA $^{5}$ (Centro da Criança e do Adolescente) da região. Dentre as intervenções realizadas, tivemos a aplicação de uma "batalha-naval" sobre mulheres importantes na ciência, a construção coletiva de uma história em quadrinhos, uma brincadeira sobre biomas brasileiros com super-heróis, e uma dinâmica circense realizada numa das quadras esportivas da EACH. Atividades de yoga para relaxamento e

\footnotetext{
${ }^{5}$ Centro da Criança e do Adolescente que desenvolve atividades com crianças e adolescentes de 6 a 14 anos e onze meses em situação de vulnerabilidade social. Ele está localizado em um bairro vulnerável e de difícil acesso, o Jardim Keralux, localizado na zona leste da cidade de São Paulo a poucos metros da EACHUSP (CRUZ, 2017).
}

concentração foram utilizadas para iniciar algumas das atividades. Tais intervenções foram planejadas pelos graduandos e são reflexo de seus interesses de pesquisas diversos, entretanto, todos eles se dão em torno do lúdico, o fator-chave que dá identidade ao grupo.

Durante as reuniões buscamos construir um contexto de formação com foco no respeito pelo saber, portanto, sempre realizamos leituras sobre temáticas diversas como, o lúdico, metodologias de análise, o papel da mulher na ciência, divulgação científica, entre outras, assim como, realizamos oficinas e discussões. Como o grupo é bem diverso, com alunos de distintos cursos de graduação, pós graduação e professores doutores, estávamos inseridos em um ambiente rico do ponto de vista de construção de conhecimento, além de fomentar a vertente interdisciplinar, articulando também as artes e as humanidades, pois estar ali possibilitava uma rica troca de conhecimento. As leituras eram propostas por todos do grupo e não havia hierarquia nisso. Os integrantes propunham leituras conforme seus temas de pesquisa e conforme a necessidade que viam do debate de alguma temática.

Além disso, como aporte teórico metodológico nos debruçamos em conhecer melhor a investigação praxeológica (OLIVEIRAFORMOSINHO (2015b, c) e verificar maneiras de adaptá-la ao nosso contexto formativo do M.A.R.I.A. A tomada de dados foi feita de forma ética, com autorização de todos os envolvidos seguindo as orientações do Conselho Nacional de Ética em Pesquisa (CONEP) e pensando na ciência educacional da práxis, utilizando os seguintes instrumentos de coleta de dados:

Gravações das reuniões semanais realizadas com o intuito de obter os discursos, as visões e as colocações dos graduandos mediante as demandas e os temas que lhes foram apresentados. A ideia foi buscar nos dados subsídios que nos mostrassem o que os motivavam a estar na linha, informações que nos ajudassem a entender suas visões a respeito da proposta da linha, entre outros fatores.

Recursos da Web - Foram analisadas as participações individuais nos aplicativos que utilizamos como ferramenta de comunicação, como "whatsapp e facebook" entre outros. A partir desses instrumentos buscamos entender se houve engajamento, comprometimento, interesse nas temáticas propostas, participação nas discussões, etc.

Diário de bordo - Todos os graduandos receberam um caderno de anotações com a 
finalidade de servir de instrumento para a sistematização, anotação e organização das ideias e informações que julgassem importantes. Esse diário deveria ser utilizado quando quisessem trazer referências para o grupo, anotar fatos importantes no decorrer das aplicações que eles realizam no CCA com intuito de não esquecerem, sugestões, críticas e elogios à estrutura e metodologia adotada no grupo, entre outros pontos. O diário foi concebido baseado na ideia de obter dados a partir das escritas dos graduandos sobre como se dá sua participação no grupo.

Entrevistas com vídeo: Foram realizadas de maneira individual com o objetivo de conhecer mais do âmbito pessoal de cada um. Iremos aqui apresentar alguns pontos da analise das entrevistas tendo em vista o contexto social dos integrantes do grupo e de que forma tal cenário influencia em seu discurso, postura, atitudes e assim 0 marque ideologicamente (KLEBA; WENDAUSEN, 2009; SILVA; SILVA, 2011; GOHN, 2004; GOHN, 2005).

Conversas individuais - Tendo em vista que muitas vezes os graduandos propõem ideias, apresentam suas opiniões em momentos de descontração e impessoais, é possível que tais falas possam ser levadas em consideração, tendo em vista que isso se faz presente e acontece de maneira corriqueira.

Apresentaremos adiante os resultados da proposta por meio dos dados coletados.

\section{RESULTADOS}

Ao analisarmos a visão dos alunos sobre como se dava a gestão das atividades realizadas nos momentos de reunião ou nas relações como um todo do grupo que compõe a linha, selecionamos algumas falas para exemplificar suas impressões a respeito da metodologia adotada na linha M.A.R.I.A. Vale ressaltar que três monitores já estavam no grupo desde 2017, sendo eles os monitores G, E e Y. Esses monitores puderam expressar suas opiniões sobre a condução dada nas formações tendo como comparativo a metodologia adotada anteriormente, em que os alunos não tinham espaço de decisão e escolha. Da mesma forma, os novos monitores, L, $\mathrm{M}$ e A que vieram de outras linhas de pesquisa, demonstraram em suas falas que compartilhavam em seus anteriores locais de atuação do mesmo modelo de metodologia, em que o coordenador direcionava as atividades e não havia autonomia nem liberdade de escolha na definição das atividades que iriam realizar nas intervenções de divulgação científica. Portanto em ambos os casos, novos e antigos monitores puderam comparar o ambiente participativo atual com o adotado em suas experiências anteriores que foram diferentes.

A monitora $L$, que é uma integrante nova do grupo, que foi realocada da linha de pesquisa chamada E.M.M.A. (Estudos da Mulher e das Minorias na Arte-Ciência) para o M.A.R.I.A., no período de coleta de dados deste estudo, foi questionada por meio de entrevista sobre de que forma a sua estada em ambas as linhas possa ou não exercer influência em sua formação. A esse respeito ela diz:

"Foi bacana porque eu não tinha tido contato com criança e ainda que o E.M.M.A. não tenha proporcionado dar aula, participar das aplicações me ajudou sim porque eu tive contato com criança pra sacar que era aquilo que eu realmente queria fazer".

Essa monitora está matriculada em uma curso de licenciatura e nesta fala percebemos que o público atendido e o tipo de atividade realizada na divulgação científica foi importante porque ela ainda não havia feito estágio e estar nas atividades ajudou nesse sentido, de ter um contato prévio com o futuro público de sua profissão. Tal contato com crianças e jovens se dá em todas as linhas de pesquisa do projeto Banca da Ciência.

Sobre a forma como o M.A.R.I.A. tem sido conduzido, tendo em vista um contexto participativo, no qual os alunos são protagonistas das ações, realizamos esse questionamento aos monitores nas entrevistas individuais e obtivemos alguns relatos bem interessantes. Dentre eles está o da monitora $G$ que em sua fala mostra acreditar que o atual formato do M.A.R.I.A. acrescentou em sua formação acadêmica no sentido de ser um espaço de realização de pesquisa. Nesse sentido ela inclusive faz um comparativo com a proposta do R.I.T.A. (Ritmos na Investigação da Tecnologia e da Arte-Ciência), grupo da qual ela já fez parte anteriormente, ressaltando a diferença e a contribuição do formato adotado pela linha de pesquisa M.A.R.I.A.

"Acho que pesquisa, principalmente porque a gente precisa de ideias e querendo ou não no R.I.T.A. a gente não pesquisava, a gente fazia o que o coordenador mandava a gente fazer. Então essa questão de pesquisa, de você ter um problema e ter que resolver esse problema e ter uma proposta com essa coisa da criatividade...fazer acontecer. Aprendi mais fortemente com o M.A.R.I.A., até escrever né, porque o primeiro projeto que eu escrevi foi para - M.A.R.I.A. e eu nunca escrevi nada para o R.I.T.A." 
Essa fala mostra que a autonomia na condução de sua pesquisa foi importante, pois, ao ter esse espaço no grupo, no qual ela tinha que fazer pesquisa, planejando atividades, coletando dados, e analisando os dados, findando na escrita de relatórios e apresentação de trabalhos em eventos. Isso foi bem importante para sua formação individual.

Em relação à organização das atividades, entendemos que dar autonomia é importante para que o monitor se coloque como responsável pela sua pesquisa e atuante, no sentido de elaborar e propor o que julga ser mais interessante e pertinente, conforme seu objetivo de pesquisa. Sendo assim, os monitores planejavam suas atividades e traziam para o debate no grupo. Explicitavam seus objetivos, sua relação com o lúdico e diziam quais atividades prévias deveriam ser realizadas e com base nisso, realizavam a divisão de tarefas. De forma democrática as tarefas eram divididas, para que cada um pudesse contribuir de alguma forma na atividade. Além disso, semanalmente os alunos recebiam tarefas para serem realizadas no decorrer da semana, como escrita de ata, relatórios de atividades, leituras, entre outras, envolvendo-os na dinâmica constante do grupo mesmo que que não se desse de maneira presencial.

Sobre a condução realizada de maneira participativa, obtivemos nas entrevistas as visões positivas, bem como, as negativas que subentendem todo o processo. Quanto aos aspectos positivos na condução do grupo e a respeito das relação que se formaram, a monitora Y comenta:

"Eu gosto da interação (...) acho que entrei no grupo certo, eu consigo me comunicar, consigo falar o que eu quero, as vezes, eu sei eu tenho a liberdade para falar mesmo não falando e eu gosto disso, dessa relação interpessoal que a gente tem".

Tal relato demostra que ela se sente em um espaço no qual ela tem voz e que será ouvida quando quiser se colocar. No decorrer do semestre houve momentos em que ela se posicionou em relação a algumas situações de forma ativa. Ainda sobre o atual formato do grupo, $\mathrm{Y}$ relata que:
"Eu acho que de todas as transições que tiveram, nessa eu consigo olhar e falar: agora eu sei o que está acontecendo! Porque antes era muito confuso, eram $\mathrm{n}$ pessoas com $\mathrm{n}$ projetos e a gente não sabia para quem se reportar, pra quem tirar dúvidas, era uma coisa nossa (põe a mão no rosto), era muito confuso (...) e agora eu já sei que eu tenho um projeto, que eu posso trabalhar em cima dele, que é minha linha de pesquisa, eu sei aonde eu posso buscar referências, diferente de como era nas outras formações".

Seu relato demonstra que ela percebe nos encontros das reuniões, um espaço de pesquisa, no qual ela atua ativamente fazendo sua pesquisa própria e que as discussões do grupo a direcionou na busca por referências específicas para sua pesquisa. Ao ser perguntado à $Y$ sobre o que ela sente falta na coordenação do grupo, ela disse:

"Eu não tinha entendido muito essas propostas dos textos, o por que que a gente está lendo, aí você falou que era para elaborar o relatório e aí quando eu sentei para fazer o relatório aí eu falei: agora eu entendi porque precisava dos textos e senti que eram poucos textos. Vi que era importante e agora que estou sentando pra fazer, devia ter lido mais, agora vou ter que correr atrás".

Tal fala demonstra que ela passou a perceber a importância dos momentos formativos por meio de leitura e que tal atividade interfere diretamente em sua pesquisa. Além disso, ela visualiza a necessidade de mais leitura e entende o espaço das reuniões como um momento de estudos.

Após essa fala conversamos sobre o trabalho que fazemos necessitar de organização e comprometimento. Essas colocações feitas de forma descontraída foram bem interessantes de ouvir, pois ela demonstra, assim como outros a preocupação de alguns integrantes que querem que tudo dê certo e que prezam pela organização pelo comprometimento de todos. Faz uma sugestão de melhoria em seu diário de bordo, demostrando ter liberdade de colocação, que pode ser visto na imagem a seguir: 
Figura 1. Sugestão de melhoria feito pela Y.

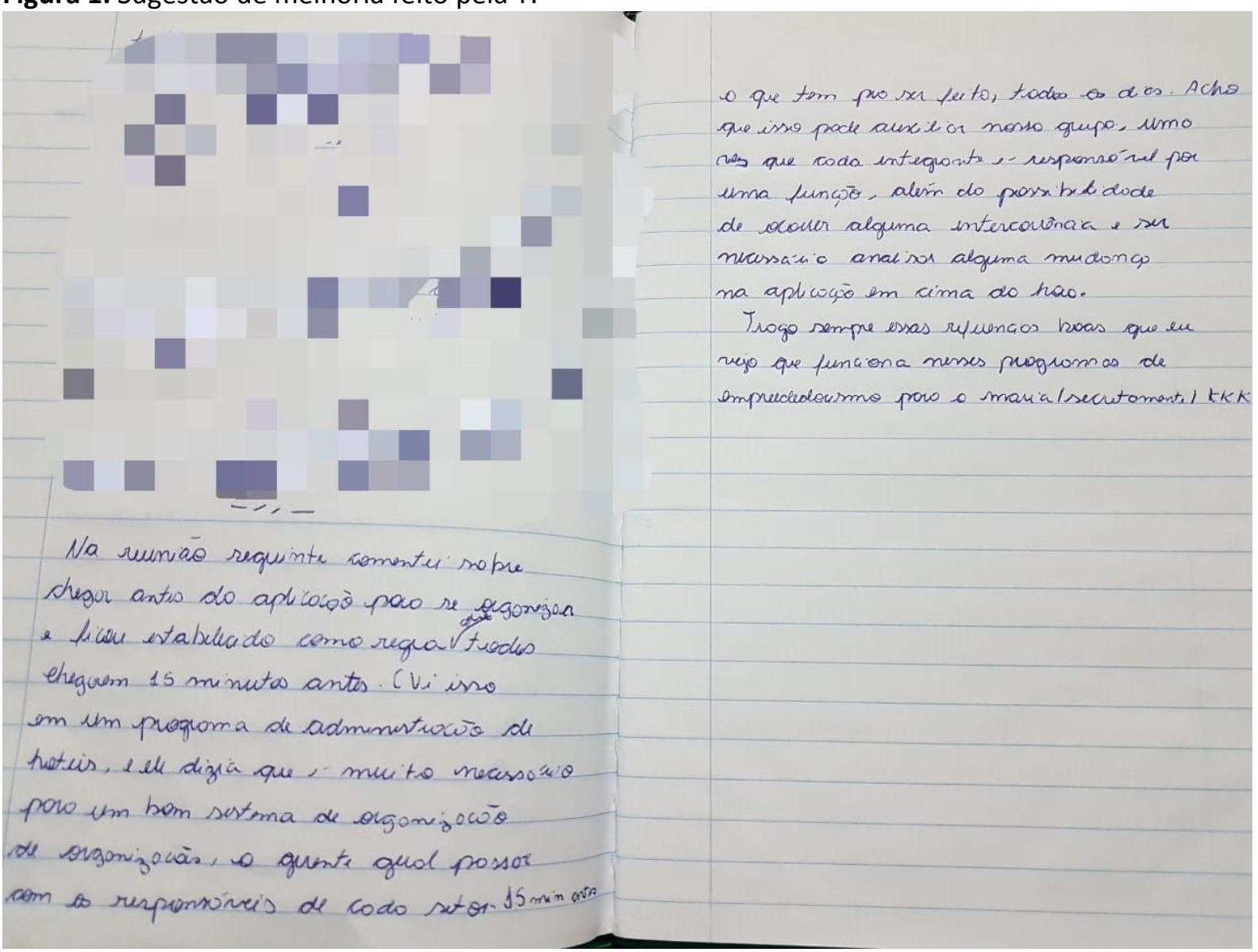

Fonte: Diário de bordo pessoal da monitora Y.

A monitora $G$ comenta a respeito da bagagem necessária para a análise de uma situação de pesquisa. Ela relata que:

"O que eu sinto falta também é de saber olhar para aquilo, por exemplo, a criança falou alguma coisa que eu achei interessante. É tipo, olhar para aquilo e saber analisar aquilo e referenciar aquilo e ter uma base, para entender o que está acontecendo e conseguir vincular a teoria dentro de uma prática, por isso que quando você falou a proposta do artigo eu falei 'ah, seria interessante ler Bakhtin, porque ele faz análise de discurso, e é uma coisa bem mais profunda, manja, difícil e complexa de entender".

Percebemos nessa fala a necessidade que a graduanda está tendo de mais direcionamento e de leituras que a ajude em sua pesquisa e na construção de um olhar mais crítico de um fato a ser analisado.

No balanço que fizemos no final do semestre sobre as atividades do grupo, esse ponto foi colocado em pauta e discussão e houve concordância que a postura deles deve mudar em relação a organização e cuidado na preparação das atividades. Falamos sobre o cuidado que devemos ter com as pessoas que estão recebendo os resultados de tudo isso, que são as crianças e adolescentes do CCA e da responsabilidade que devemos ter em proporcionar a eles o melhor, e fazer o que nos propomos a fazer, divulgar ciência por meio do lúdico suscitando neles o interesse pela ciência.

Nas reuniões temos incentivado a participação dos integrantes do grupo e temos dado abertura para se colocarem. Devido a prática de leitura de bibliografias que julgamos pertinentes ao contextos das atividades de pesquisa que concerne à linha de pesquisa M.A.R.I.A., percebemos que os integrantes passaram a sugerir leituras. Ao debater um texto que versava sobre lúdico, brinquedos e brincadeiras da Kishimoto (2002), que falava sobre os brinquedos serem construídos por pessoas que carregavam concepções ideológicas e que tais visões apareciam nesses objetos, entramos na temática de análise de discurso e a monitora $Y$ comentou sobre uma disciplina que fez sobre Análise do discurso tendo como aporte teórico Baktin e sugeriu de lermos em algum momento no grupo, ressaltando ser bem interessante sua 
leitura. Já o monitor A propôs a leitura do livro "Pedagogia do Oprimido" de Paulo Freire nas nossas reuniões de formação pois achava importante ler um teórico da educação e isso foi acatado pelo grupo. Tais sugestões mostram que os integrantes tem participado no sentido de propor leituras e tem visto esse momento de leitura como algo importante no processo de formação do grupo.

Ao analisarmos as transcrições dos áudios das reuniões percebemos que há um equilíbrio entre as falas da coordenadora com as falas dos monitores. Por mais que haja variações na quantidade de falas quando relacionamos um monitor com outro, pois em determinados assuntos alguns se manifestavam mais e outros menos, quando fazemos um balanço geral de todas as reuniões, percebemos que todos se colocam de alguma forma nas situações vivenciadas nas atividades de divulgação científica e nas demandas da reunião. Tal equilíbrio mostra que conseguimos criar um ambiente participativo e interativo.

A ideia de coletividade também esteve presente e foi construída, pois nos momentos de discussões sobre a melhor decisão a se tomar em relação às intervenções, os monitores se posicionavam, sugeriam alteração e os responsáveis pela atividade se mostravam abertos a tais colocações. Além disso, o comprometimento com o coletivo se dava também na divisão de tarefas, pois quando um não podia participar, outro se propunha a realizar a tarefa. Esses exemplos dados são um recorte de algumas das impressões que obtivemos dos dados analisados frente a proposta participativa que criamos.

\section{DISCUSSÃO}

De maneira geral, podemos dizer que a proposta de criação de um ambiente coletivo de estudos participativo foi positiva pois os participantes se viam dentro da linha de pesquisa e realizavam suas pesquisas individuais de, se sentiam livres para se colocarem e tal característica os incentivavam na realização das atividades.

Uma das propostas apresentadas na construção desse ambiente participativo foi a necessidade de sustentar nossas ações na teoria, ou seja, realizarmos a práxis, que é uma ação fecundada na teoria. Para isso a rotina de leituras de referências que julgássemos importantes para a condução das pesquisas era necessária e percebemos que não conseguimos realiza-la efetivamente, pois a densidade de leitura foi baixa.
As outras demandas acabavam atrapalhando a sistematização disso e vemos que isso foi percebido pelos monitores. A esse respeito elas disseram sentir falta de mais leituras.

Percebemos que a autonomia dada não poderia ser tão ampla, pois ao deixarmos os monitores tomarem muitas decisões, algumas ações não foram bem pensadas. Precisamos refletir sobre formas de conduzi-los sem que se sintam podados em sua autonomia, pois mesmo com liberdade de atuação é necessário que os monitores sejam direcionados. Cabe salientar que eles receberam direcionamento, porém, tiveram mais autonomia de decisão e isso resultou em casos no qual o monitor se comprometia com algo e não realizava. Isso se refletia na organização e nos resultados das atividades deles mesmos ou de seus colegas de grupo.

De maneira geral, tivemos atividades bem pensadas e elaboradas mas em contrapartida tivemos atividades realizadas sem nenhum planejamento e cuidado. No início do semestre organizamos as atividades do grupo de forma a debatermos as intervenções com antecedência e elaboramos um calendário de aplicação para que todos tivessem ciência da sua data e se planejasse com antecedência, tendo em vista, organização de materiais, leituras para planejar o que fazer na intervenção, como realizar a coleta de dados, etc. Sentimos que algumas falhas devem ser sanadas na construção e condução de um ambiente de pesquisa, como, organização, mas os dados mostram que a metodologia de condução do grupo de pesquisa foi eficiente e trouxe bons resultados aos participantes como um todo, dando liberdade de fala, exigindo pró-atividade e crescimento pessoal e profissional.

\section{REFERÊNCIAS}

BOMTEMPO, E. Brincadeira simbólica: Imaginação e criatividade. In: BOMTEMPO, E.; GOING, L. C. Felizes e brincalhões: Uma reflexão sobre o lúdico na educação. Rio de Janeiro: Wak Editora, 2012.

BOMTEMPO, E. Brincar, fantasiar, criar e aprender. In: OLIVEIRA, V.B. 0 brincar e a criança do nascimento aos seis anos. Petrópolis, RJ: Vozes, 2005.

BRONOWSKI, J. O olho visionário: ensaios sobre arte, literatura e ciência. Brasília: UNB, 1998.

CRUZ, L. D. Centro para Crianças e Adolescentes: o caso do CCA Jardim Keralux. 64 f. 2017. 
Monografia. (Faculdade de Educação) Universidade de São Paulo, São Paulo, 2017.

GOHN, M. Empoderamento e participação da comunidade em políticas sociais. Revista Saúde e Sociedade, v. 13, n. 2, p. 20-31, mai./ago. 2004.

GOHN, M. O protagonismo da sociedade civil: movimentos sociais, ONGs e redes solidárias. São Paulo: Cortez, 2005.

KISHIMOTO, T. M. (Org.) O brincar e suas teorias. São Paulo: Pioneira Thompson Learning, 2002.

KLEBA, M. e WENDAUSEN, A. Empoderamento: processo de fortalecimento dos sujeitos nos espaços de participação social e democratização política. Revista Saúde e Sociedade, v.18, n.4, p.733-743, 2009. DOI: 10.1590/S0104$12902009000400016 . \quad$ Disponível em: http://www.scielo.br/scielo.php?script=sci arttext \&pid=S0104-

$12902009000400016 \&$ lng=pt\&tlng=pt. Acesso em 19/07/18:

NASCIMENTO JUNIOR, F. A. Crise de identidade: gênero e ciência nos quadrinhos de super-heróis. 2017. Tese (Doutorado em Educação) - Faculdade de Educação, Universidade de São Paulo, São Paulo, 2017. Disponível em: <http://www.teses.usp.br/teses/disponiveis/48/48 134/tde-07082017-155126/>. Acesso em: 20/07/18.

OLIVEIRA-FORMOSINHO J. A formação em contexto: A mediação do desenvolvimento profissional praxeológico. In: CANCANCIAN, V. A. (ed.), Formação e políticas para educação infantil: crianças, infâncias e docências na educação infantil. Brasil: 2015a.

OLIVEIRA-FORMOSINHO J. A investigação praxeológica: revisitando estudos sobre $\mathrm{O}$ desenvolvimento profissional. ReLAdEI: Revista Latinoamericana de Educación Infantil, 2015b.

OLIVEIRA-FORMOSINHO J. A formação em contexto: uma revisão de literatura sobre o conhecimento profissional praxeológico. ReLAdEI Revista Latinoamericana de Educación Infantil, 2015c.

OLIVEIRA-FORMOSINHO, J.; FORMOSINHO, J. Pedagogia em participação: a perspectiva educativa da Associação Criança", 2015. Disponível em:

https://www.researchgate.net/publication/28350 0319_PEDAGOGIA_EM_PARTICIPACAO. Acesso em: 03 jul. 2017.

RAMOS, J. E. F. O cômico e a física: o riso, a quebra de expectativa e o absurdo no ensino e na divulgação da física. 279 f., 2016. Tese (Doutorado em Educação). Faculdade de Educação da USP Universidade de São Paulo, 2016.

SILVA, R. S., SILVA, V. R. Política Nacional de Juventude: trajetória e desafios". Cad. CRH, Salvador, v. 24, n. 63, p. 663-678, Dez. 2011. Disponível em: $<$ http://www.scielo.br/scielo.php?script=sci_arttex t\&pid=S0103-

$49792011000300013 \& \operatorname{lng}=e n \& n r m=i s o>$. Acesso em: 07 fev. 2018.

SANTOS, F. R. Detetive ou cientista? A literatura policial infanto-juvenil como recurso didático na educação em ciências. 112 f., 2013.Dissertação (Mestrado em Educação). Faculdade de Educação da USP - Universidade de São Paulo, 2013.

SERRÃO, M.; CARVALHO, C. O que dizem os educadores de infância sobre o jogo. Revista Iberoamericana de Educación. Revista Iberoamericana de Educação, n.55/5/15, p. 1-15, jun, 2011.

Submetido em: 30/08/2018

Correções Obrigatórias: 12/11/2018

Aceite Final em: 03/12/2018 